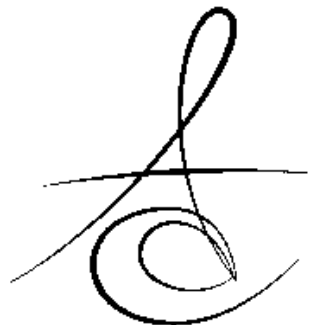

Makale Kodu/Article code: 2332

Makale Gönderilme tarihi: 30.06 .2015

Kabul Tarihi; 20.08.2015

\section{OBSTRUKTİF UYKU APNESİ VE DİŞ HEKİMLİĞİ}

OBSTRUCTIVE SLEEP APNEA AND DENTISTRY

Dr. M.Abdullah KELEŞ*
Doç Dr Ş. Begüm TÜRKER*

\begin{abstract}
öz
Obstruktif uyku apnesi, uyku esnasında üst hava yolunun tamamının veya bir kısmının tekrar ederek kapanması nedeniyle uykunun bölünmesi ve oksijen desaturasyonu ile karakterize yaygın bir rahatsızlıktır. Bu rahatsızlık, özellikle kişinin gündüz fonksiyonlarını olumsuz etkileyerek ve hayat kalitesini azaltarak çok sayıda hastalığa neden olur. Bu çalışmanın amacı obstruktif uyku apnesinin ortaya çıkmasında rol alan nöromüsküler ve anatomik faktörleri incelemektir. Burundan sürekli pozitif hava yolu basıncı tedavide ilk seçenektir, ağız apareyi tedavisi, ciddi olan vakalar dahil hastaların yarısında obstruktif uyku apnesini kontrol etmede etkilidir. Obstruktif uyku apnesi tedavisinde başarılı olabilmek için tedavinin kontrendikasyonları ve endikasyonları, aparey dizaynı, tedavi basamakları ve orofaringeal obstruksiyon bölgelerinin bilinmesi önemlidir.
\end{abstract}

Anahtar Kelimeler: Uyku apnesi, Mandibular ilerletme, Ağız içi apareyleri

Sağıklı ve dengeli bir hayat için intiyaç duyulan uyku süresi kişinin genetik faktörlerine bağlı olarak değişmektedir. Uyku bozuklukları ile ilgili bilgi birikimi, Kryger ve ark. tarafından 1989 yılında başlamış ve son 20 yılda katlanarak artmıştır. ${ }^{1}$ Uyku sağığı hızlı gelişen bir disiplindir. Bu disiplinde uyku bozuklukları ile ilgilenen KBB, göğüs hastalıkları, nöroloji, psikiyatri, kardiyoloji dalları bulunmaktadır. Multidisipliner yaklaşım ile uyku bozukluğuna bağlı solunum parametreleri saptanmakta ve hastalara tedavi olanağı sunulmaktadır. ${ }^{2}$ Multidisipliner yaklaşımın önemi göz ardı edilmemelidir. Yapılan araştırmalar; uyku bozukluğuna bağlı solunum,

\section{ABSTRACT}

Obstructive sleep apnea is a common disorder characterized by repetitive, complete or partial closure of the upper airway during sleep, resulting in sleep fragmentation and oxygen desaturation. The disorder causes significant morbidity, particularly in terms of impairment of daytime functioning and the impact this has on quality of life. The aim of this study is to review the neuromuscular and anatomic factors in the pathogenesis of obstructive sleep apnea. Nasal continuous positive airway pressure is the current treatment of choice. Oral appliance therapy is also effective in controlling obstructive sleep apnea in half of patients, including some patients with more severe forms of obstructive sleep apnea. Knowledge of contraindications and indications for treatment, appliance design, steps of treatment and oropharyngeal obstruction areas are very important to obtain success in treatment of obstructive sleep apnea.

Keywords Sleep apnea, Mandibular advancement, Oral appliances

nokturnal parafonksiyon, uykuya bağlı hareket bozuklukları ve son olarak uyku-orofasiyal ağrının birbiriyle olan bağlantısını ortaya çıkarmaktadır. ${ }^{3} \mathrm{Bu}$ konuda sahip olunacak daha fazla bilgi ve beceri ile hastaların tedavilerinde daha kapsamlı yaklaşım söz konusu olacaktır. Sürekli pozitif havayolu basıncı (CPAP) uyku apnesinin tedavisinde ilk sıradaki yerini korumaktadır. Fakat mandibular ilerletici apareyler (MAD) de tedavide önemli bir rol oynamaktadır. Ağız içi aparey tedavisi için diş hekiminin; okluzyon, temporomandibular rahatsızlıklar ve hareketli aparey tedavisi konularına hakim olması gerekmektedir. ${ }^{2}$

\footnotetext{
* Marmara Üniversitesi Diş Hekimliği Fakültesi, Protetik Diş Tedavisi AD
} 


\section{İNSİDANS VE GÖRÜLME SIKLIĞI}

Uyku bozukluğuna bağlı solunum rahatsılıkları toplumda oldukça yaygındır ve çoğunlukla hastalar farkında değildir. Bu sendrom uykunun sürekliliğini bozar, kişiyi yarı uykulu halinde tutar ve uykunun kalitesini düşürür. Eğer uykudan uyanma durumu çok sık ise veya çok uzun sürüyorsa bu durum çok sayıda nörokognitif probleme yol açabilir. Havayolu akışının problemli olması oksijen desaturasyonuna sebep olur. Uykunun yetersiz olması ve oksijenlenme problemleri birçok sonucu beraberinde getirmektedir. Meydana gelen bu sonuçlar kişiyi etkilemekte ve sosyal hayata adaptasyonunu sekteye uğratmaktadır. ${ }^{4}$

Obstruktif Uyku Apnesi (OSA) medikal bir teşhistir. Ancak diş hekimi ağız içi aparey tedavisine başlamadan önce; polisomnografi (PSG) sonuçlarını, mevcut radyografileri, uyku uzmanının tavsiyelerini, klinik geçmişi ve dental muayeneyi gözden geçirerek uyku bozukluğunu değerlendirmelidir. MAD (mandibulayı önde konumlandıran aparey) tedavisi başladıysa, tedaviden önceki detaylı objektif ve subjektif dökümanlar tedavinin etkinliğinin değerlendirilmesi için bir referans noktası olacaktır. $^{5}$

Klinik anamnezde; horlama varlığı ve şiddeti, şahit olunan apnelerin varlığı ve şiddeti, gündüz aşırı uyku halinin varlığı ve şiddeti, gün içersindeki enerji seviyesi, uyku kalitesi (skala 1-10 arası), uyku miktarı (bir gecede uyunan saat), gece uykudan uyanma sayısı, uyku pozisyonu (yan, sırt üstü, yüz üstü) ve diğer semptomların (yakın zamanda kilo artışı, bruksizm, sabahleyin baş ağrısı, gastroözofagal reflü hastalığı, depresyon, impotans, nazal tıkanıklık) varlığı hastaya sorulmalıdır. ${ }^{2}$

Uyku apne-hipopne sendromunun toplumdaki görülme sıklığı konusunda araştırmalarda farklı rakamlar belirtilmiştir fakat erkeklerde \% 3-7, kadınlarda \% 2-5 arasında olduğu tahmin edilmektedir. ${ }^{6}$ Özellikle orta yaş kategorisinde, görülme sıklığı kadınlarda \% 9' lara çıkarken, erkeklerde \% 24' lere kadar çıkmaktadır.7 Görülme sıklı̆̆ı; coğrafya, etnik köken ve ekonomik faktörlere göre değişim göstermektedir. Kadınlarda menopoz ve obezite uyku apnesi için risk faktörleridir. ${ }^{8}$ OSA görülme sıklığının başta Amerika olmak üzere obezitenin yaygınlaştığı toplumlarda zamanla daha çok artacağı öngörülmektedir. ${ }^{9}$

\section{Dental Anamnez}

Hastalar, ağız içi aparey tedavisine uygun bir aday olup olmadıklarının değerlendirilmesi için dental muayeneye tabi tutulurlar. Hastanın, ortodontik veya periodontal tedavi hikayesinin varlığı sorgulanmalıdır. Geniş kapsamlı bir ağız içi muayene tedavi risklerinin değerlendirilebilmesini sağlar. Periodontal muayene yapılır. Çiğneme kasları ile beraber TME değerlendirilir. Okluzal analiz yapılır, parafonksiyonel alışkanlıkların tespiti sağlanır. Dolgu, kanal tedavisi, çekim gereksinimi olan dişler tespit edilir. ${ }^{2}$

\section{ANAMNEZ VE KLİNİK BULGULAR}

OSA; metabolik rahatsızlıklara (bozulmuş glikoz ve lipit metabolizması, sistemik enflamasyon), kardiyovasküler rahatsızlıklara (hipertansiyon, kalp yetmezliği, kalp krizi, arteriyal fibrilasyon), gün içinde aşırı uyku haline, motorlu taşıt kazası riskinin artmasına, bozulmuş yaşam kalitesine, depresyona ve bilişsel bozukluklara neden olabilir. ${ }^{2}$

Mevcut dental radyografiler herhangi bir dental patolojik durum varlığı açısından incelenmelidir. ${ }^{10}$ Ağız içi apareyle tedavi başarısını öngörebilmek ve aparey kullanımı ile oluşabilecek kraniyofasiyal değişimleri incelemek adına sefalometrik filmler de kullanılır. Kısa yumuşak damağı olan ve mandibular düzlem ile hyoid kemik arası mesafenin az olduğu hastaların aparey tedavisi için daha uygun adaylar olduğu belirtilmiştir. ${ }^{11}$ BT ve MR gibi diğer görüntüleme teknikleri göstermiştir ki mandibular ilerletme ile faringeal havayolu genişliği ve hacmi artmaktadır. Havayolu hacmindeki artış OSA tedavisinde $M A D^{\prime}$ in pozitif etkisini gösterdiğinden, tedavi öncesi görüntüleme başarının öngörülmesinde faydalı olabilir. ${ }^{12}$

Günümüzde hastanın tedaviye cevabı açısından anatomik ve fizyolojik bulguların değerlendirilmesi çok güvenilir olmasa da, hastanın anatomisini ve velofaringeal-orafaringeal boşluklar üzerindeki olası sınırlayıcı etkenleri anlamak; OSA'nin sebeplerinin anlaşılmasında, MAD tedavisi için hasta seçiminde ve tedavi beklentilerinin oluşturulmasında yardımcıdır. Dar boyuttaki havayoluna; iskeletsel yapılar, adenoid ve dil gibi genişlemiş yumuşak dokular, yumuşak damağın şekli veya obezite sebep olur. ${ }^{13}$

\section{Palato-Faringeal Değerlendirme \\ Mallampati Sınıflaması}

Amerikan Uyku Tıbbı Akademisi uyku apnesinin değerlendirilmesinde Modifiye Mallampati Skorlamasının kullanımıı tavsiye etmektedir. ${ }^{5}$ Değerlendirme 
sırasında hastanın başı yere dik olacak şekilde pozisyonlandırılır. Dilin ağız içerisindeki rahat pozisyonu; dilin hacmi ve ağız içerisinde olduğu zaman havayolu ile olan ilişkisi gözlemlenir. Daha sonra hastaya dilini dışarıya çıkarması söylenir ve hastanın dilinin uzunluğu, tonsilleri, uvulası, yumuşak damağın ebatları, posterior orofarinks incelenir, ilgili yapıların daha rahat görülebilmesi için dil aparatından faydalanılabilir. Uvulanın tabanı ve yumuşak damağın görünümü gözlenir ve skorlanır. ${ }^{14}$

\section{TEŞHİS}

OSA sendromunun teşhisi; kapsamlı bir uyku geçmişi anamnezi, mevcut karakteristik klinik özelliklerin saptanması ve uykuya bağlı solunum rahatsızIığının objektif olarak gösterilmesini kapsar. ${ }^{15}$ Sadece medikal anamnez ile bile OSA için yüksek riskli hastalar teşhis edilebilir. ${ }^{16}$

\section{Tonsil Boyutu}

Bazı çalışmalarda tonsil ebatlarıyla AHI değeri arasında korelasyon rapor edilirken, bazı çalışmalarda rapor edilmemiştir ${ }^{17,18}$ (Tablo 1).

Tablo 1. Tonsil Sınıflaması

\begin{tabular}{|c|c|}
\hline Derece & Tanım \\
\hline 0 & Hasta tonsilektomi geçirmiş \\
\hline 1 & Tonsiller, tonsilar fossa içerisinde \\
\hline 2 & Tonsiller anterior sütunun arkasında görülebilir \\
\hline 3 & $\begin{array}{c}\text { Tonsiller, boşluğun 3/4'ünü kapatmıştır, orta } \\
\text { hatta doğru yer alırlar }\end{array}$ \\
\hline 4 & $\begin{array}{c}\text { Tonsiller hava yolunu tamamiyle } \\
\text { kapatmaktadırlar }\end{array}$ \\
\hline
\end{tabular}

\section{OSA için Yüksek Risk Grubunda Bulunan Hastaların Özellikleri}

Obezite (Vücut kütle indeksi 35'ten büyük hastalar), konjestif kalp yetmezliği, tedaviye dirençli hipertansiyon, tip 2 diyabet, nokturnal ritm bozuklukları, kalp krizi ve pulmoner hipertansiyon hastaları OSA için yüksek risk grubunu oluştururlar. Anketler rutin sistemik sağılk değerlendirmesinin bir parçasıdır. En çok kullanılan anketler "Berlin Anketi", "Epworth Uykululuk Ölçeği" ve "STOP-Bang Anketi" 'dir. STOPBang Anketi apne olasılığının öngörülmesinde daha büyük klinik fayda sağlamaktadır. "STOP-Bang Anket" skoru 3 veya daha fazla maddede pozitif ise hasta yüksek riskli OSA grubu içinde kabul edilir. ${ }^{19}$

STOP-Bang Anketinde hastalara; horlama, yorgunluk, gözlemlenmiş apne, hipertansiyon ve obezite (Vücut kütle indeksi 35'ten büyük) varlığı sorulur. Yaş (50'den büyük), boyun kalınlığı (40cm'den büyük), cinsiyet (erkek) tespit edilir.

Eğer tarama sonucu pozitif çıkarsa değerlendirmeyi doğrulamak için ilave sorular sorulabilir. Hastanın yatak partneri ile görüşülmesi tavsiye edilir, çünkü partneri hasta uyurken direkt gözlem yapabildiği için ilave bilgiler sağlayabilir. ${ }^{20}$

Uyku apne sendromunun teşhisi sadece hasta anamnezine, ankete ve klinik bulguların saptanmasına dayanmaz. Aynı zamanda anormal solunum olaylarının polisomnografi (PSG) veya evde uygulanan test yöntemi ile gösterilmesi gerekir. Bu sebeple, diş hekimi OSA'den şüphelendiği zaman kapsamlı bir uyku değerlendirmesi için uyku bozuklukları ile ilgilenen tıp hekimiyle konsültasyon yapmalıdır. ${ }^{21}$

\section{Fiziksel Özelliklerin Değerlendirilmesi}

Hastaların obez olup olmadığı (boyun kalınlığı erkeklerde $40 \mathrm{~cm} /$ kadınlarda 38 cm'den büyük; Vücut Kitle İndeksi $35^{\prime}$ ten büyük), kraniyofasiyal anatomi varlığı (retrognati, mikrognati, tonsiller hipertrofi, makroglosi, hyoid kemiğin inferiorda konumlanmış olması orafaringeal havayolunu daraltır) ve hipertansiyon varlığı değerlendirilir (özellikle ilaca karşı dirençli tip). ${ }^{2}$

\section{Objektif Test}

Diş hekimi, yorumlamadan önce, gerek evde yapilan testler olsun gerek gece boyu süren uyku testleri olsun kalifiye bir uyku bozukluklarıyla ilgilenen KBB uzmanı, göğüs hastalıkları uzmanı veya nöroloji uzmanı tarafından yapılan değerlendirmelere ihtiyaç duyar. OSA'nın teşhisinde altın standart polisomnografidir (PSG). PSG' de, teknik personel tarafından elektroensefalogram, elektrookulogram, nazal basınç, oksijen saturasyonu, solunum eforu, elektrorkardiyogram, elektromyogram, ses kaydı, görüntü kaydı gibi fizyolojik sinyaller kayıt edilir. Elektroensefalogramda, apne ve hipopnelerin toplam miktarı, toplam uyku saati sayısına bölünür ve $\mathrm{AHI}$ değerini verir. ${ }^{21}$

Apnede, solunum 10 saniyeden daha fazla kesilir. Hipopnede ise uykudan uyanma ve oksijen saturasyonundaki düşüş söz konusudur, hava akışı azalır fakat solunum tam olarak durmaz. ${ }^{2}$

OSA Sınıflaması elde edilen AHI değerlerine göre yapılır, (AHI): Uyku esnasında bir saat içinde meydana gelen apne ve hipopnelerin sayıları toplamıdır. AHI değeri 5-15 arasında ise hafif OSA, 15-30 arasında ise orta OSA, 30'un üzerinde ise şiddetli OSA teşhisi konur. Hipersomnia, insomnia, yorgunluk, bilişsel problemler, koroner arter hastalığı, hipertansiyon, kalp krizi

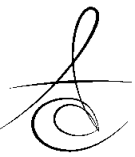


geçmişi, myokard enfarktüsü, pulmoner hipertansiyon, kalp yetmezliği ve aritmi gibi rahatsızlıklar komorbite faktörleridir. ${ }^{22}$

\section{TEDAVI}

OSA, uzun dönem takip ve multidisipliner yaklaŞım gerektiren kronik bir hastalık olarak tedavi edilmelidir. OSA için medikal, dental, davranışsal ve cerrahi tedavi seçenekleri vardır. Çoğu vakada bu seçeneklerden bir tanesi primerdir ve diğer seçeneklerle bağlantılı olarak tedavi uygulanır. Hasta, kendi tedavisinde çok önemli bir rol oynar, OSA' nın ciddiyetini anlamada, kendisine ait risk faktörlerini öğrenmede ve tedavi alternatifleri ile ilgili bilgi sahibi olmada hasta aktif rol almalıdır. ${ }^{16}$

OSA'da; pozitif havayolu basıncı (PAP) tedavisi, üst solununum yolu cerrahi tedavisi, farmakolojik tedavi, ağız içi aparey tedavisi ve davranışsal tedavi (kilo verme, alkolü bırakma, uyku pozisyonunu değiştirme vb.) olmak üzere 5 adet tedavi seçeneği bulunmaktadır. İlk olarak 1981 yılında rapor edilen PAP, üst solunum yolunu açarak tedavi eder ve halen OSA' nın standart tedavisi olarak kabul edilmektedir ${ }^{23}$ (Tablo 2).

Tablo 2. Oral Aparey Tedavisinin Endikasyonları ve Amaçları

\begin{tabular}{|c|c|}
\hline Endikasyon & Amaç \\
\hline $\begin{array}{c}\text { OSA semptomları } \\
\text { göstermeyen horlayan hastalar }\end{array}$ & $\begin{array}{c}\text { Horlamayı subjektif } \\
\text { olarak kabul edilebilir seviyeye } \\
\text { indirmek }\end{array}$ \\
\hline $\begin{array}{c}\text { Hafif ve orta şiddetteki OSA } \\
\text { olan, CPAP tedavisine uyum } \\
\text { sağlayamayan ve ağız içi aparey } \\
\text { tedavisini seçen hastalar, CPAP } \\
\text { için zayıf bir aday olan hastalar, } \\
\text { davranışsal değişim tedavisine } \\
\text { uyum sağlayamayanlar }\end{array}$ & $\begin{array}{c}\text { OSA' nın klinik işaret ve }^{\prime} \\
\text { semptomlarına çözüm sağlamak } \\
\text { AHI ve oksihemoglobin } \\
\text { saturasyon seviyelerini } \\
\text { normalleştirmek }\end{array}$ \\
\hline $\begin{array}{c}\text { Şiddetli OSA hastası olup } \\
\text { nazal CPAP tedavisine yeni } \\
\text { başlayanlar } \\
\text { Üst solunum yolu } \\
\text { cerrahisinden önce ağız içi aparey } \\
\text { tedavisi gereken hastalar }\end{array}$ & $\begin{array}{c}\text { OSA' nın klinik işaret ve }^{\prime} \\
\text { semptomlarına çözüm sağlamak } \\
\text { AHI ve oksihemoglobin } \\
\text { saturasyon seviyelerini } \\
\text { normalleştirmek }\end{array}$ \\
\hline
\end{tabular}

PAP tedavisi, bilevel PAP ve oto-titre PAP şekillerinde uygulanabilir. Nazal maskeler en çok kullanılan çeşittir fakat ağızdan hava kaçması tedavi etkinliğini azaltabilmektedir. Oronazal maskeler (tam yüz maskesi olarak da bilinir) oral ve nazal solunuma izin verir fakat eğer cihazı sıkılaştırırken mandibula ve dil posteriora doğru konumlanırsa apneyi daha kötü hale getirme riskleri vardır. Oronazal maskeler, burundan solunumu kısıtlı hastalar tarafından sıklıkla tercih edilmektedir. ${ }^{24}$

Pozitif havayolu basıncının (PAP), semptomları iyileştirdiği, işyeri ve trafik kazalarını azalttığı, artmış olan sempatik aktiviteyi azalttığı ve özellikle arteriyal hipertansiyon olmak üzere kardiyovasküler hastalıkları azalttığı ispatlanmıştır. ${ }^{25}$

Sürekli pozitif havayolu basıncl (CPAP), AHI değerini düşürür ve pozitif sonuçlar verir. Ancak pahalı oması, burun ve yüze verdiği rahatsızlık hissi nedeniyle eleştirilere maruz kalmaktadır. Sonuç olarak bu yan etkiler, hastanın tedaviye rıza göstermesine olumsuz etki etmekte ve diğer tedavi seçeneklerinin araştırılmasına sebep olmaktadır. ${ }^{26}$

Yaşam biçimini değiştirmek, uyku esnasında supin pozisyonundan kaçınmak, solunum rahatlatıcı burun aparatları kullanmak, ağız içi aparey tedavisi uygulamak ve üst solunum yolu cerrahisi tedavisi alternatif tedavi yaklaşımlarıdır . ${ }^{4}$

Ağız içi aparey tedavisi, sürekli pozitif havayolu basıncı (CPAP) ile horlama tedavisine ve sürekli pozitif havayolu basıncı (CPAP) tedavisini reddeden hafif ve orta şiddetteki OSA hastalarının tedavisinde alternatif olarak ortaya çıkmıştır. Mandibular ilerletme apareyleri ile tedavi, sürekli pozitif havayolu basıncı (CPAP) ile tedaviden daha az etkili görünse de her iki tedavinin de etkili olduğu durumlarda hastalar ağız içi aparey tedavisini tercih etmişlerdir. ${ }^{2}$

\section{Ağız İçi Apareylerin Çalışma Mekanizması}

Ağız içi aparey tedavisi, dil ve mandibulayı anterior ve inferior yönde konumlandırarak hava yolu kollapsını azaltmak yöntemiyle çalışır. Tedavinin amacl; üst havayolu koridorunu genişleterek OSA' yı ve horlamayı azaltmaktır. ${ }^{27}$

Üst hava yolu 3 bölgeden oluşur:

1- Velofarinks: Sert damak ile uvulanın uç kısmı arasındaki bölge

2- Orofarinks: Uvulanın uç kısmı ile epiglot arasındaki bölge

3- Hipofarinks: Epiglot ile ses telleri arasındaki bölge

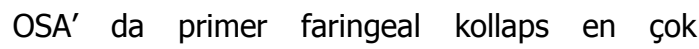
velofarinks bölgesinde olmaktadır. ${ }^{28}$ Mandibulayı önde konumlandıran apareyler, velofaringeal ve orofaringeal bölgede lateral duvarları genişletir. ${ }^{29}$

Literatürdeki uyku apnesi ve horlamanın tedavisinde ağız içi apareylerin kullanımını inceleyen klinik çalışmalara bakıldığında, değişkenlerin (takip süresi, ölçülen solunum değişkenleri, başarı oranının ölçümü, sonuçların sunumu ve test edilen ağız içi apareyin tipi gibi) homojen olmadığı ağız içi apareyin öncesinde ve ağız içi apareyle birlikte yapılan gecelik diyagnostik testlerin süresi ve tipinin de farklılık gösterdiği görül-

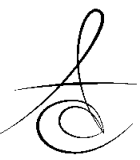


mektedir. AHI değerinin 5 'ten düşük olması başarılı kabul edildiğinden, mandibulayı önde konumlandıran aparey (MAD) tedavisi ile başarı \% 19 ile \% 75 arasında değişkenlik göstermiştir, AHI değerinin 10' dan düşük olması başarılı kabul edildiğinde ise başarı oranları \% 30 ile $\% 94$ arası değişmektedir. ${ }^{30-45}$

Araştırmalarda MAD tedavisinin; kan basıncı, kardiyak fonksiyon, endotelyal fonksiyon, oksidatif stres işaretleyicileri ve simule sürüş performansı üzerine olumlu etkileri rapor edilmiştir. ${ }^{33,38,40}$ MAD tedavisi; hastanın AHI değerlerini düşürerek fizyolojisini iyileştirmekle kalmamış, aynı zamanda gün içindeki uyku halini azaltarak hayat kalitesini yükseltmiştir. ${ }^{46}$

MAD, CPAP tedavisi ile birlikte de kullanılabilir. Tam yüz maskesi kullanan hastalarda karşılaşılan mandibulanın retrüze olması problemi için de kombine tedavi uygulanabilmektedir. Kombine tedavi ile ilgili sonuçlar umut vaat etse de günümüzde bu konuda yeterli bilimsel kanıt bulunmadığı için daha fazla araştırma yapılması gerekmektedir. ${ }^{2}$

\section{Ağız İçi Aparey Tipleri}

OSA tedavisinde kullanılan ağız içi apareyler; dil tutucu apareyler (Tongue Retaining Devices-TRD), yumuşak damak kaldırıılar (Soft Palate Lifters-SPL, Soft Palate Elevators-SPE) ve mandibulayı önde konumlandıran apareyler (Mandibular Advancement Devices - MAD)'dir. ${ }^{2}$

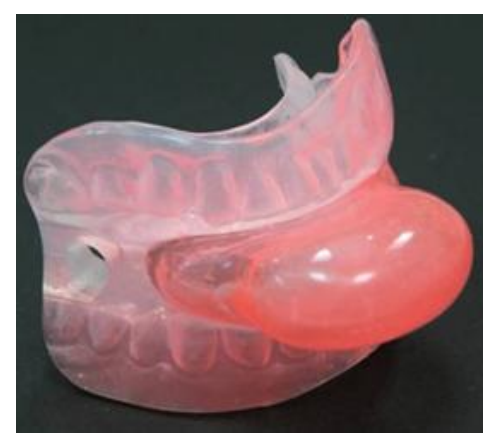

Resim 1. Dil Tutucu Aparey (TRD)

TRD, emme etkisi yaratarak dili oral kavitede anterior kısımda tutar böylece dil pozisyonunu iyileştirerek üst hava yolunu genişletir. TRD'de dişlerden ankraj alınmadığından; hipodonti, dişsizlik ve ciddi periodontal hastalık durumlarında TRD önemli bir tedavi alternatifi teşkil etmektedir. ${ }^{2}$

Üzerinde en çok araştırma yapılan, hakkında en kapsamlı bilgiye sahip olunan ve en çok tercih edilen aparey $M A D^{\prime}$ dır. MAD alt ve üst dişleri örter ve mandibulayı dinlenme pozisyonuna göre daha ön konumda tutar.

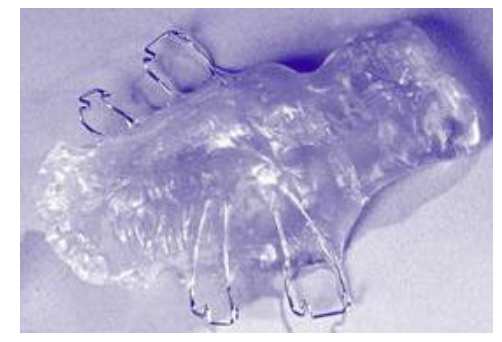

Resim 2. Yumuşak Damak Kaldırıcı (SPL)

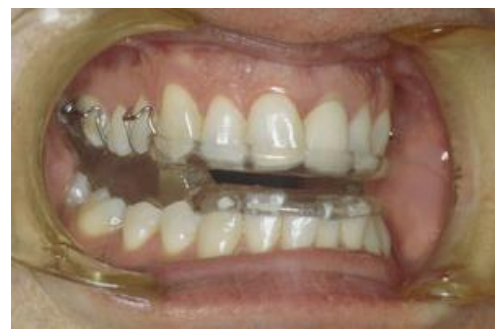

Resim 3. Mandibular Advancement Device (MAD)

MAD'lar iki çeşittir. Bunlar; hastaya özel üretilen apareyler; Titrasyon yapılabilen (iki parçadan oluşan aparey), titrasyon yapılamayan (tek parçadan oluşan aparey) ve prefabrike apareylerdir.

Farklı ağız içi apareylerin etkinliklerinin karşılaştırıldığı çalışmaların analizinde hastaya özel üretilen MAD'ların birbirine net bir üstünlük kuramadığı, aralarında anlamlı bir fark olmadığı görülmüştür. Ancak, hastaya özel üretilen MAD'lar prefabrike olanlara göre tedaviye verilen olumlu cevap açısından belirgin olarak üstün bulunmuşlardır. ${ }^{2}$

Tek ya da çift arktan sağlanacak iyi bir retansiyon, artmış dikey boyutta mandibulanın yeterli protrüzyonu ve çene hareketlerini vertikal ve lateral yönde kısıtlamayan apareyler TME ile uyumlu olması MAD'ın sahip olması gereken özellikleridir. MAD'ların daha efektif olması için, her iki dental arktan retansiyon sağlanmalııı. Dizaynda metalik çubuk, tüp mekanizması, inter-ark elastik, metal veya plastik bağlayıcılar veya magnetler yer alabilir. ${ }^{2}$

MAD apareyi; invaziv değildir, CPAP cihazlarına göre küçük ve portatiftir, güç kaynağına intiyaç duymaz, rahat kullanılabilir ve maliyeti düşüktür. ${ }^{5}$

\section{MAD Tedavisinde Hasta Seçim Kriterleri}

Tedaviye başlamadan önce OSA varlığının veya yokluğunun kesin olarak saptanması gerekir. Uykuyla ilişkili solunum yolu problemlerinin şiddeti uyku bozuk-

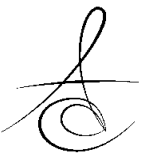


lukları ile ilgilenen tıp hekimi tarafından PSG veya portatif monitör yardımı ile saptanarak, MAD tedavisi için hasta diş hekimine yönlendirilir. Doğru teşhis konulmadan tedaviye başlanması hasta açısından büyük risk teşkil eder. Tedavi aşamasından önce mutlaka; hastalık tipinin doğru teşhisi, santral apne olup olmadığının saptanması, hipoventilasyon sendromu, oksijen desaturasyonun şiddeti veya solunum ile ilgili problemlerin şiddetinin bilinmesi gerekmektedir. MAD ile tedavi yetişkinlerle sınırlıdır çünkü çocuklarda bu apareyi kullanabilmek için literatürde yeterli kanıt desteği bulunmamaktadır. Literatürde, santral uyku apnesi ve hipoventilasyon sendromu gibi diğer uykuyla ilişkili solunum problemlerinin tedavisinde MAD'ın klinik rolü ile ilgili yapılmış hiçbir çalışma bulunmamaktadır. ${ }^{47}$ Hangi hastanın ağız içi aparey tedavisine yanıt vereceğini kesin olarak öngörmek henüz mümkün değildir. ${ }^{48}$

\section{Protrüzyonun Derecesi}

MAD'ı etkin kılabilmek için mandibulanın protrüzyonu şarttır. ${ }^{30}$ OSA'yı önlemek için gerekli olan mandibular protrüzyon miktarı ve vertikal açıkık miktarı belirsizdir. Rapor edilen protrüzyon miktarı 6$10 \mathrm{~mm}$ arasında veya maksimum protüzyonun $\% 65-$ $70^{\prime}$ i arasında değişmektedir. ${ }^{49}$

\section{TARTIŞMA VE SONUÇ}

MAD; OSA ve horlamanın tedavisinde endikedir. MAD'lar çoğu hafif ve orta şiddetteki OSA hastasında etkilidir. Klinik geçmiş, bulgular ve PSG'ye dayanarak uyku bozuklukları ile ilgilenen tıp hekimi tarafından hasta değerlendirilir ve diş hekimine yönlendirilir. OSA'nın olası sebepleri ve olası risk faktörlerini saptayabilmek için hastanın diş hekimi tarafından değerlendirilmesi gereklidir. Tedaviye verilecek cevap; hastanın var olan özellikleri ve durumuna, OSA' nın şiddetine ve mandibulanın protruziv kapasitesine bakılarak belli oranda öngörülebilir. Diş hekimi hastalarını değerlendirirken, horlama varlığını ve apneik ve/veya hipopneik olayları değerlendirmeli ve bunlara uyku bruksizminin eşlik edip etmediğini irdelemelidir. Eğer uyku bruksizmi mevcut ise, uyku solunum bozukluğunun tedavisinin bruksizmin dental etkilerinin tedavisinden önce geldiği unutulmamalıdır. ${ }^{50}$

Uyku bozuklukları ile ilgilenen uzman tıp hekimleri ile birlikte multidisipliner çalışmak, tedavi planının uygunluğuna emin olmak ve tedavinin risk ve faydalarının doğru değerlendirmek açısından zorunludur. Cerrahlarla işbirliği de önemlidir, nazal solunumun geliştirilmesi ve velofarinkste meydana gelen kollapsın azaltılması için MAD tedavisi öncesinde tedavinin etkinliğini sağlamak için cerrahi müdahale gerekebilir. MAD, CPAP ve cerrahi tedavi OSA tedavisinde birbirine eşit seviyede farklı tedavi alternatifleri değillerdir. Her bir tedavinin; hasta tercihi, OSA şiddeti, medikal komorbidite faktörleri ve kraniyofasiyal özellikler gibi kompleks faktörlerin kombinasyonu dahilinde tedavi içinde kendine özgü bir yeri vardır. Diş hekimleri ve uyku hekimleri hastaya en büyük faydayı sağlamak amacıyla OSA tedavisinde kendilerine ait sorumluluğu yerine getirmelidir. Uyku hekimleri, MAD tedavisine uygun hastaya CPAP tedavisi başlamak yerine diş hekimine yönlendirmelidir. Aynı şekilde diş hekimi de CPAP tedavisi endikasyonu olan ve bu tedaviye uyum sağlayabilecek hastaları uyku kliniğine yönlendirmeli ve gerekli olan durumlarda tedaviye dahil olmalıdır. OSA tedavisinde diş hekimi ve uyku hekimi arasında işbirliği esastır. Uykunun normalleştirilmesi ve oksijen saturasyonunun iyileştirilmesi apne tedavisinde ilk amaçtır. ${ }^{2,51,52}$

Dental uyku tıbbı yeni bir alan olmasına rağmen, bu alanda hızla büyük çalışmalar yapılmakta ve ilerleme sağlanmaktadır. Aparey dizaynının tedavi sonuçlarını nasıl etkilediği ile ilgili ve MAD tedavisine olan uyumu objektif şekilde değerlendirilebilmek ve tedavi süresini kIsaltabilmek için tek gecede uygulanan MAD titrasyonunun başarısını artıracak çalışmalar yapılmalidır.

OSA tedavisinde kullanılan ağız içi apareyleri yapacak hekimin TME rahatsızıklarını, hareketli aparey tedavisini ve okluzyon tedavisini bilmesi gerekmektedir. Diş hekiminin multidisipliner yaklaşımda olması ve uyku konusunda uzman hekimlerle koordineli olarak çalışması ile uyku apnesinde oral apareylerin uygulanması, doğru ve mükemmel tedavi yaklaşımlarının sağlanması mümkün olacaktır.

\section{KAYNAKLAR}

1. Kryger MH, Roth T, Dement WC. The Principles And Practice Of Sleep Medicine. WB Saunders, St Louis: 1989. p. 739.

2. Barewal RM, Hagen CC. Management of Snoring and Obstructive Sleep Apnea with Mandibular Repositioning Appliances: A Prosthodontic Approach. Dent Clin N Am 2014;58:159-80.

3. Moldofsky $\mathrm{H}$. Sleep and pain. Sleep Med Rev 2001;5:385-96. 
4. Lavigne G, Cistulli $P$, Smith $M$. Sleep medicine for dentists: a practical overview. Quintessence Publishing, Chicago: 2009.

5. Epstein LJ, Kristo D, Strollo PJ. Clinical guideline for the evaluation, man agement and long-term care of obstructive sleep apnea adults. J Clin Sleep Med 2009; 5:263-76.

6. Punjabi NM. The epidemiology of adult obstructive sleep apnea. Proc Am Thorac Soc 2008;5:136-43.

7. Young T, Palta M, Dempsey J. The occurrence of sleep-disordered breath- ing among middle-aged adults. N Engl J Med 1993;328:1230-5.

8. Bixler EO, Vgontzas AN, Lin HM. Prevalence of sleep disordered breathing in women. Am J Respir Crit Care Med 2001;163:608-13.

9. Young T, Peppard PE, Taheri S. Excess weight and sleep-disordered breathing. J Appl Physiol 2005;99:1592-9.

10. Ferguson KA, Cartwright $R$, Rogers $R$. Oral appliances for snoring and obstructive sleep apnea: a review. Sleep 2006;29:244-62.

11. Eveloff SE, Rosenberg CL, Carlisle CC. Efficacy of a Herbst mandibular advancement device in obstructive sleep apnea. Am J Respir Crit Care Med 1994;149:905-9.

12. Gao XM, Zeng XL, Fu MK. Magnetic resonance imaging of the upper airway in obstructive sleep apnea before and after oral appliance therapy. Chin J Dent Res 1999;2:27-35.

13. Vos W, De Backer J, Devolder A. Correlation between severity of sleep apnea and upper airway morphology based on advanced anatomical and functional imaging. J Biomech 2007;40:2207-13.

14. Nuckton TJ, Glidden DV, Browner WS. Physical examination: Mallampati score as an independent predictor of obstructive sleep apnea. Sleep 2006;29:903-8.

15. American Academy of Sleep Medicine Task Force. Sleep-related breathing dis- orders in adults: recommendations for syndrome definition and measurement techniques in clinical research. Sleep 1999;22:667-89.

16. Epstein $\sqcup J$, Kristo $D$, Strollo PJ. Clinical guideline for the evaluation, man agement and long-term care of obstructive sleep apnea adults. J Clin Sleep Med 2009;5:263-76.

17. Yagi H, Nakata $S$, Tsuge H. Morphological examination of upper airway in obstructive sleep apnea. Auris Nasus Larynx 2009;36:444-9.
18. Thong JF, Pang KP. Clinical parameters in obstructive sleep apnea: are there any correlations? J Otolaryngol Head Neck Surg 2008;37:894-900.

19. Chung F, Subramanyam R, Liao P. High STOPBang score indicates a high probability of obstructive sleep apnoea. $\mathrm{Br} J$ Anaesth 2012;108:768-75.

20. Netzer NC, Stoohs RA, Netzer CM. Using the Berlin Questionnaire to identify patients at risk for the sleep apnea syndrome. Ann Intern Med 1999;131:485-91.

21. McNicholas WT. Diagnosis of obstructive sleep apnea in adults. Proc Am Thorac Soc 2008;5:154-60.

22. International classification of sleep disorders. Diagnostic and coding manual. $2^{\text {nd }}$ edition, American Academy of Sleep Medicine, Westchester: 2005.

23. Sullivan CE, Issa FG, Berthon-Jones M. Reversal of obstructive sleep apnea by continuous positive pressure applied through the nares. Lancet 1981;1:862-5.

24. Beecroft J, Zanon S, Lukic D. Oral continuous positive airway pressure for sleep apnea: effectiveness, patient preference, and adherence. Chest 2003;124:2200-8.

25. Chobanian AV, Bakris GL, Black HR. Seventh report of the Joint National Committee on Prevention, Detection, Evaluation, and Treatment of High Blood Pressure. Hypertension 2003;42:1206-52.

26. Giles TL, Lasserson TJ, Smith B. Continuous positive airway pressure for obstructive sleep apnoea in adults. Cochrane Database Syst Rev 2006;1:10-6.

27. Kyung SH, Park YC, Pae EK. Obstructive sleep apnea patients with the oral appliance experience pharyngeal size and shape changes in three dimensions. Angle Orthod 2005;75:15-22.

28. Isono S, Tanaka A, Tagaito Y. Pharyngeal patency in response to advancement of the mandible in obese anesthetized persons. Anesthesiology 1997;87:1055-62.

29. Sutherland K, Deane S, Chan A. Comparative effects of two oral appliances on upper airway structure in obstructive sleep apnea. Sleep 2011;34:469-77.

30. Mehta A, Qian J, Petocz P. A randomized controlled study of a mandibular advancement 
splint for obstructive sleep apnea. Am J Respir Crit Care Med 2001;163:1457-61.

31. Gotsopoulos H, Chen C, Qian J. Oral appliance therapy improves symp toms in obstructive sleep apnea: a randomized, controlled trial. Am J Respir Crit Care Med 2002;166:743-8.

32. Johnston $C D$, Gleadhill IC, Cinnamoond $M J$. Mandibular advancement ap pliances and obstructive sleep apnoea: a randomized clinical trial. Eur J Orthod 2002;24:251-62.

33. Barnes M, McEvoy RD, Banks S. Efficacy of positive airway pressure and oral appliance in mild to moderate obstructive sleep apnea. Am J Respir Crit Care Med 2004;170:656-64.

34. Blanco J, Zamarron C, Abeleira P. Prospective evaluation of an oral appliance in the treatment of obstructive sleep apnea syndrome. Sleep Breath 2005;9:20-5.

35. Naismith SL, Winter VR, Hickie IB. Effect of oral appliance therapy on neu robehavioral functioning in obstructive sleep apnea: a randomized controlled trial. J Clin Sleep Med 2005;1:374-80.

36. Petri N, Svanholt P, Solow B. Mandibular advancement appliance for obstructive sleep apnoea: results of a randomised placebo controlled trial using parallel group design. J Sleep Res 2008;17:221-9.

37. Randerath WJ, Heise M, Hinz R. An individually adjustable oral appliance vs continuous positive airway pressure in mild-to-moderate obstructive sleep apnea syndrome. Chest 2002;122:569-75.

38. Hoekema A, Stegnenga B, Wijkstra PJ. Obstructive sleep apnea therapy. J Dent Res 2008;87:882-7.

39. Gagnadoux F, Fleury B, Vielle B. Titrated mandibular advancement versus positive airway pressure for sleep apnoea. Eur Respir J 2009;34:914-20.

40. Bloch KE, Iseli $A$, Zhang JN. A randomized controlled crossover trial of two oral appliances for sleep apnea treatment. Am J Respir Crit Care Med 2000;162: 246-51.

41. Pitsis AJ, Darendeliler MA, Gotsopoulos H. Effect of vertical dimension on efficacy of oral appliance therapy in obstructive sleep apnea. Am J Respir Crit Care Med 2002;166:860-4.

42. Tegelberg $A$, Walker-Engstrom ML, Vestling $O$. Two different degrees of mandibular advancement with a dental appliance in treatment of patients with mild to moderate obstructive sleep apnea. Acta Odontol Scand 2003;61:356-62.
43. Gauthier L, Laberge L, Beaudry M. Efficacy of two mandibular advancement appliances in the management of snoring and mild-moderate sleep apnea: a cross-over randomized study. Sleep Med 2009;10:329-36.

44. Vanderveken OM, Devolder A, Marklund M. Comparison of a custom-made and a thermoplastic oral appliance for the treatment of mild sleep apnea. Am J Respir Crit Care Med 2008;178:197202.

45. Aarab G, Lobbezoo F, Hamburger HL. Effects of an oral appliance with different mandibular protrusion positions at a constant vertical dimension on obstructive sleep apnea. Clin Oral Investig 2010;14:339-45.

46. Randerath WJ, Verbraecken J, Anderas S. NonCPAP therapies in obstructive sleep apnoea. Eur Respir J 2011;37:1000-28.

47. Cistulli P, Gotsopoulos H, Marklund M. Treatment of snoring and obstructive sleep apnea with mandibular repositioning appliances. Sleep Med Rev 2004;8:443-57.

48. Hoffstein V. (). Review of oral appliances for treatment of sleep-disordered breathing. Sleep Breath 2007;11:1-22.

49. Charkhandeh S, Topor ZL, Grosse JC. Target protrusive position from mandibular protrusion titration: is it a good estimate of adequate protrusion? Sleep Breath 2012;16:919-31.

50. Lavigne GJ, Khoury S, Abe S. Bruxism physiology and pathology: an over- view for clinicians. J Oral Rehabil 2008;35:476-94.

51. Kurtulmuş $H$, Çötert $S$, User $A$, Bilgen C. Horlama ve obstruktif uyku apnesinde tanı ve tedavi. EÜ Dişhek Fak Derg 2007;28:19-31.

52. Karakış D, Biçer AZY, Gültepe E. Management of an obstructive sleep apnea patient with a mandibular advancement splint: a case report. J Dent Fac Atatürk Uni 2013;3:385-91.

\section{Yazışma Adresi}

Dr. Ş. Begüm Türker

Marmara Üniversitesi

Diş Hekimliği Fakültesi

34854 Başıbüyük

İstanbul, Türkiye

Tel: 02164211621 (1777)

Fax: 02164210291

e-mail: begumturker@hotmail.com 